\title{
Analysis on the Construction of Book Information Management System
}

\author{
Xiang'ai Kong, Guimin Xia \\ Qufu Normal University, Jining, 273100, China
}

Keywords: Book information, Library, Management system construction

\begin{abstract}
In the information society, the manual book management system is unable to adapt to the development of modern library services. It is an issue to use science and technology to improve the efficiency of library information management. This paper points out the functional requirements and performance requirements of the book information management system, and constructs the user login module, the lending management module, the book inquiry module and the data statistics module to provide some references for relevant researchers.
\end{abstract}

\section{Introduction}

Library has rich literature and information resources, and it is an important component of social information system. It plays a more and more important role in information society. In the wave of information technology, the network revolution under the impact of library management business has been a strong impact, with the continuous increase in the collections of books, data entry and query difficulty also increases accordingly, library management and traditional service cannot meet the needs of readers of literature information retrieval in the information era. How to use advanced information technology to improve the management and service level of science and technology books is a new challenge we are facing. Now, in the university library has adopted the library information management system, but in the library information management departments of the University, teachers and students to find books and materials are still using traditional query methods, borrowing a local search to the classification frame, so that not only it is difficult to find the books they need, but also time-consuming. The administrator in handling loan registration, query borrowing records, managers must be one by one to find in the library records, and to find the borrowing records and delete the record is a very troublesome thing, not easy to statistics. Books and information departments of the university is not a sound management system, which is not provided for the total number of books, no provisions of the loan period, resulting in many books borrowed after long time not to return, because the books are not timely reminders also can easily lead to the loss of books. Therefore, it is necessary to apply library information management system to the library information management of each department. The establishment of library information management system not only frees the administrators from the traditional books and materials management, but also improves the efficiency.

\section{Demand Analysis of Book Information Management System}

Functions Demand Analysis. We connect the school library and the library of the various departments through the internet. At the beginning of the school year, there will be freshmen registration, there will be new staff, the library to each new and teaching staff information to establish personal files, apply for library card. When students graduate and transfer their staff and workers, the library shall delete the information of each student and faculty, and the information of the students and teaching staff who have not completed the book shall not be deleted. Every new book, the library to each book information management and input, so as to refer to. When the books are overdue, they 
should be fined and recorded when the books are returned. Penalties may also be accumulated, to a certain amount, the reader must return, more than the number of days before the return of the fine, will receive a certain late fee. You can query the book, along with the increase of the amount of information, the library collection is increasing year by year, how to quickly and accurately find their own need for books that we must consider the issue of books, now we use query methods can already online query by title, author and other books to find information, support fuzzy query by keyword search. In the use of this search method, we will find a word can find a lot of books, for we don't understand the book related content, only the title is very difficult to know which book is suitable for us. Therefore, although there are special computers for books retrieval, the utilization rate is very low. When the library card is lost, it is only required to report the loss and reissue it in the school library, and the library information can be searched on the website of the library.

Performance Demand Analysis. The system allows to meet the operating system security conversion and independent operation of other applications, if the process of system operation and modify data, must be properly adjusted design software, it has greater flexibility. The key words in the corresponding region can be successfully queried, but the records that do not contain key words can not be found, which improves the precision and recall of the system information. Which appears in the development stage of the system fault processing and modification are developers, after the corresponding test, change database, operation management and maintenance implementation is set by the system administrator, the database is not allowed in normal error. University books information management system, most operations are within seconds of the time. According to the needs of you must make the software has a procedure consisting of a relatively simple structure, easy electronic equipment maintenance and management, specifically, software has a database data structure is large and simple, has a special number of the personnel involved in the operation, can be relatively simple to maintain, easy to repair. Relatively strong data processing function, because the data exchange in the library is more frequent, this requires the system to have faster response speed, not easy to error, recovery ability. Must be by hand operation of library information management system, the rights owners often just library management staff, such as lending books, when the content of the corresponding safety management part of the lost, there will be difficult to predict the consequences of each landing must verify the identity of users, especially professionals to system management and maintenance the database, which is absolutely not allowed to appear normal use of system error, if the system error of the data stream must be intact to ensure.

\section{Modules Construction of Book Information Management System}

User Login Module. The library management system is divided into administrator system administrator and the librarian, the system administrator account to the library all senior administrator after landing, the system can manage the librarian account, account login to manage user's information. The freshmen, the library will give a new username and password, username for the general students, the initial user login, the system will prompt the user to modify the password, to ensure the security of user account. To account for the security of the user's account, due to various reasons for the account and password leaks, login management module to provide users with modified password function. Modify the password, enter the original password and new password through the user, the system audit will modify the login password. Because of the development of science and technology nowadays, the popularity of various websites, forums and mailboxes makes it possible for us to have multiple accounts and passwords, plus some other factors that are not measurable, so that users can easily forget their passwords. Retrieve password function to provide services for users, users find the user password through the security information, provide more personalized service. In the face of the school every year many new entrants, improve the user registration function to provide a quick and basic user registration is a single user input register, the system provides a batch registration function, generating many registered users through the external file into the function, the external file can be a table or meet the requirements document format, greatly to improve the work efficiency. The user management module, the administrator can have 
permission to query user and administrator user information, provide general query by name, account books and other information owner, return to the user information, to facilitate the unified management of library management system.

Lending Management Module. Book lending is a basic function of the library management system, library lending need to review the user information and book information, through the audit will modify the system database in library information and user information, complete book lending. The audit does not pass the user back error information to the user. When the book returns, the library management system's basic function, when the book returns, the librarian will inspect whether the book has the breakage, as well as whether violates the library management rule, for example books expiration and so on. After the completion of the audit, modify the library books, information and user information, complete the book returns. Renew books is a unique function of the system, provide extended library time operation for the user, the user can renew through two ways, one is through the log book management system website, increase renew information; the other one is carrying books to the library and library card in the renewal process, users need to review the process of renewals the renewal conditions, each user of each book can only renew once. Users in the lending process, such as expired, will have to pay overdue fines, overdue fine before the user library card is locked, not allowed to borrow books, until the user unlock after the user after paying a fine, update the database in real time. As the information error or change or batch input for other reasons, the book information to modify the view book information through one or more input book name, book number and other basic information, and modify the book information, generally by librarians operating this function. Book delete view function book information through one or more input book name, book number and other basic information, and then delete the book information, generally by the librarian must delete operation.

Book Inquiry Module. The use of fuzzy query, only need to input the keywords, keyword books will be displayed, this inquiry method allows readers to quickly find all the books they need in the case of uncertainty, and then find their own books in these books. As we have a book storage each year, so in the use of fuzzy query case there may be a lot of information, the problem is that the book did not lend books to the content they want, even in the library to see the section distribution of this book will also appear this problem. Second, it is to borrow, check out the information which the feel good, want to read it. So, how to determine which books are what they really need is a question to consider. Solutions can be taken by a query result and book link advantage is that you can browse books after about the content and then choose whether to borrow a paper book, the disadvantage is the need to spend a lot of money to buy school books, for limited funds, there is no way to realize the school temporarily. The other is the introduction of books when inputting books and information. The advantage is that it can narrow the reader's choice to a certain extent, and the disadvantage is that it increases the workload of inputting books. The book inquiry module is an indispensable module of the library information management system. With this module, the whole system is a complete system. When readers want to borrow a book, you can first query the basic information of the book. For books information inquiry, we must first know the book number, the title of the book, the author, the publishing house, and the category, one of which can inquire the basic information of the book. After the query, the reader can consider whether to borrow the book according to the book information. We will return the book documentary number input reader, press the confirm button after the input to return books ISBN, finish the book by the confirm button. The number of books will be automatically increased in inventory. In this function, the staff returns the books according to the borrower's library card number and the returned book number. And in accordance with the actual situation may occur only know the book name, I do not know the return of the book number, so added to the book name to return the function. This function is the book borrowing function in the book name into a book number of an improved method, so as not to borrow function, like the first conversion, and then borrow. Upon completion of the return, the return report will also be printed for user inspection and confirmation

Data Statistics Module. When the reader inquiries about the book information, he decides which book to borrow. Then, in the administrator's book lending processing. When a reader chooses a book, 
the administrator first queries the reader's information from the reader's information management table to see if the reader has the right to borrow books. Then the readers borrow books processing. This is the core part of the system, can complete the book lending. The first administrator to borrow the input library card number library card number or bar code, and will display the user's name, type, can borrow copies of books. Statistics module in university library information management system which can count the entire system, according to the corresponding statistical information can be used to book problem with user library which exists in the process of the work carried out to reflect to the library book management and implementation of purchasing books provide extra help. In the statistical module of this system, the main functions include category statistics, book information statistics, financial statistics, lending books, statistics and so on. After the administrator completes the work, should carry on a statistic to the day or this month's borrowing situation. The design of the system statistics is a single time query, not a time query. This function is the unique function in the system, can provide the corresponding library time prolonged operation for the user, the user to renew the main way for the following two kinds: one is by virtue of the library management system login website, to renew information effectively increased; another way is that users will book and library card to the library to implement the whole process renew operation, renewals must renew the user conditions for review, often each book each user can only renew once. So, every day after the administrator has finished his work, he should count the number of books lent that day, and then count the total amount of books lent this month. Through statistical data can be compared, as far as possible to improve lending rates. On the same day and this month's lending statistics, the statistical data show. When the administrator to the day of borrowing statistics, select the specific date to be checked. Then click the month query button, the system will show the lending situation to the display area this month.

\section{Conclusion}

Book information management system is constructed on the basis of the actual needs of the development of database based information systems software. The system mainly completes the books, inquires, borrows, statistics and so on. By using this system, it can reduce the workload of the salesman, improve the work efficiency, and deal with the large amount of data accurately and quickly. The system developed in this paper has good operation effect, and the users used to reflect it have a friendly interactive interface.

\section{References}

[1] Yi Xiaoyu. Application Data Mining in Library Information Management System [J]. Journal of Xinxiang University (Natural Science Edition), 2013, 30(3): 192-194.

[2] Guo Wenrong. Design and Implementation of Book Information Management System of Publishing House [J]. Computer \& Network, 2017(5): 65-67.

[3] Zhuang Mei, Shao Min, ChenHui, Zhao Qingshuang. Asset management on books and reference materials in academic library supported by three-level information support system [J]. Experimental Technology and Management, 2014, 31(8): 253-255+259.

[4] Huang Zhikun. The Design and Implementation of Small-scaleLibrary Information Management System [J]. Computer Knowledge and Technology, 2016, 12(18): 69-70. 